\begin{tabular}{|c|c|c|}
\hline & Int.J.Curr.Microbiol.App.Sci (2016) 5(12): 291-294 & \\
\hline & International Journal of Current Microbiology and Applied Sciences & \\
\hline & ISSN: 2319-7706 Volume 5 Number 12 (2016) pp. 291-294 & \\
\hline EXCELLENT & Journal homepage: http://www.1jcmas.com & \\
\hline PUBLISHERS & & wwwi.jemas:con \\
\hline
\end{tabular}

Original Research Article

http://dx.doi.org/10.20546/ijcmas.2016.512.031

\title{
Prospective Study on Microbiology of Respiratory Tract Infections with Interest in Multidrug Resistant Bacteria
}

\author{
K.P. Aswathi ${ }^{1}$, B.J. Deepthy ${ }^{2 *}$, Gogi Suresh ${ }^{2}$, P.V. Harish ${ }^{2}$ and U.V. Deepthy ${ }^{1}$ \\ ${ }^{1}$ Department of Microbiology, School of Health Sciences, University of Calicut, India \\ ${ }^{2}$ Department of Microbiology, DM WIMS Medical College, Wayanad, India
}

*Corresponding author:

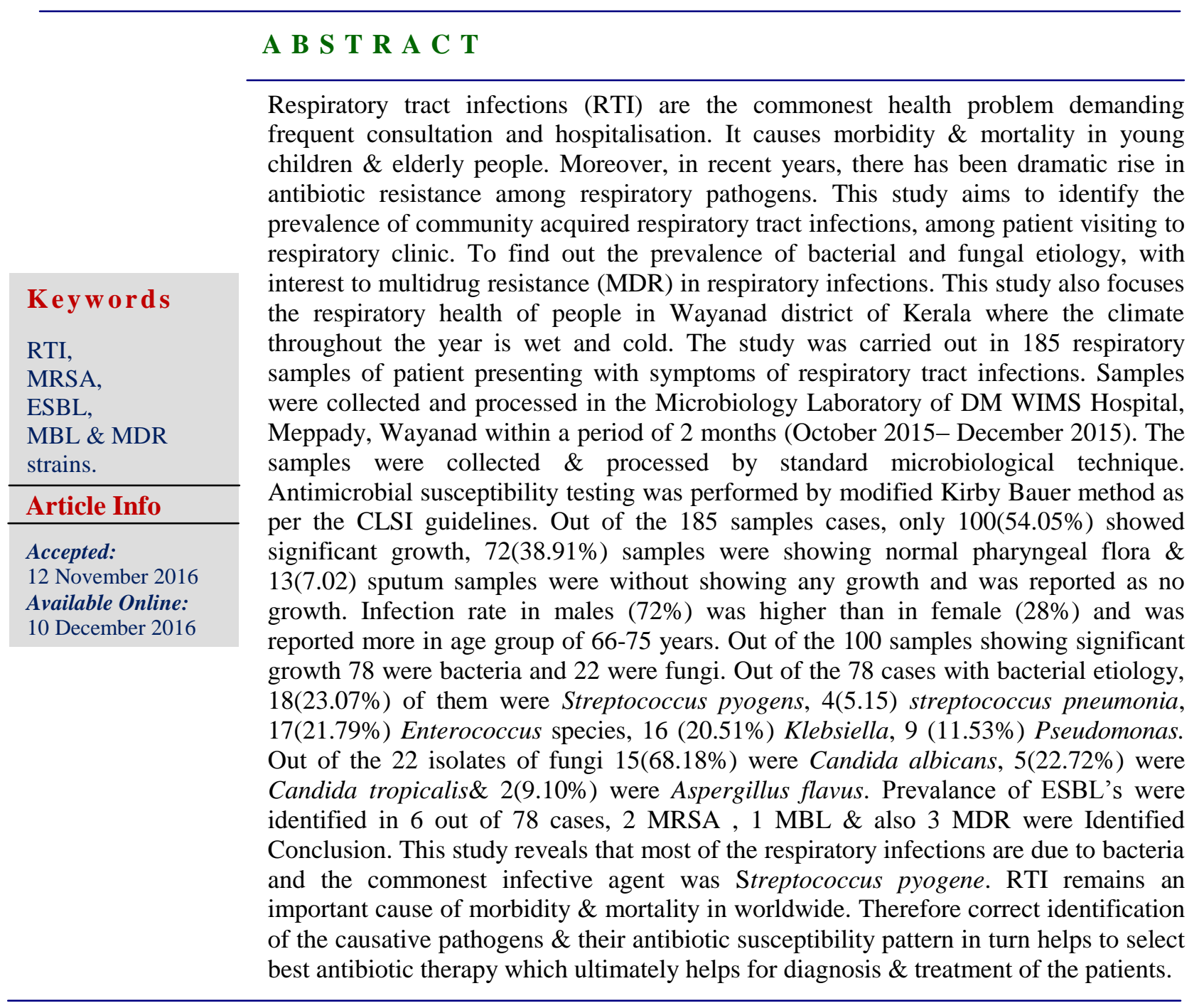




\section{Introduction}

Respiratory tract infections (RTI) are among the most common infectious diseases of human's worldwide (Carroll, 2002). Infections of the respiratory tract are responsible for $4.4 \%$ of all hospital admission \& $6 \%$ of all general practitioner consultations (Anderson et al., 1993). Infections occur by air borne route through inhalation. Coughing \& sneezing spread the infection, close contact in school, at work \& visit to the hospital also may lead to the transfer of causative agents. The infections are common during winter season (Elliot $e t$ al., 1996). Respiratory Tract Infections are persistent health problems \& being a common reason for consultation \& hospitalization, impose an enormous burden on society (Woskey et al., 2001). They also account for $3 \%-5 \%$ of deaths in adults, especially over the age of 60 years. However, increasing antibiotic resistance in frequently isolated respiratory tract pathogens has complicated the selection process of antimicrobial agents (Guthrie, 2001). The dramatic rise in the antimicrobial resistance among the respiratory pathogens is a matter of potential concern worldwide (Mukhopadhyay et al., 2003). This study was conducted to find out the prevalence of respiratory tract infections among the people of Wayanad District.

\section{Materials and Methods}

The present study was carried out in the Department of Microbiology, DM WIMS Medical College, Meppadi, Wayanad, Kerala, India. This was carried out during a period of 3 months, from October 2015 January 2016. A total of 185 respiratory samples were collected. Respiratory specimens like sputum, Bronchial wash, Throat swab, Endo tracheal secretion \& Nasal swabs were collected from patients attending to pulmonology department. The samples were processed according to standard conventional methods and isolates were identified by biochemical tests. Antibiotic susceptibility testing was done by Kirby-Bauer disk diffusion method on Muller- Hinton agar and interpreted as per CSLI guidelines (CLSI, 2012). The isolates showing reduced susceptibility to carbapenems (imipenem and meropenem) were selected for detection of Metallo-beta lactamases (MBLs) enzyme by imipenemEDTA disk method.

\section{Results and Discussion}

Out of 185 respiratory specimens studied, bacterial growth was noted in 100 samples, 72 samples showed the growth of normal flora \& remaining 13 samples were without any growth. Out of the 100 cases with significant respiratory tract infections, $39(39 \%)$ were in the age group of 66-75 and $33(33 \%)$ cases were in the age group of 5665 years.

Out of the 78 bacterial isolates, $18(23.07 \%)$ were streptococcus pyogenes, $4(5.12 \%)$ Streptococcus pneumonia, 17(21.79\%) Enterococcus species, 3(3.84\%) were Staphylococcus aureus, 7(8.97\%) were E.coli, 16 (20.51\%) were Klebsiella species, 9(11.53\%) were Pseudomonas, and 3(3.84\%) identified as Acinetobacter. Out of the 22 fungal isolates, $15(68.18 \%)$ were Candida albicans, 5 (22.72\%) were Candida tropicalis \& 2 (9.09\%) were Aspergillus flavus. The study also reveals that respiratory tract infections are more prevalent in male patients than females. Emergence of serious infections due to multidrug resistant organisms poses a therapeutic challenge. Antibiotic resistance analysis revealed the multiple drug resistance of the isolates to the commonly used antibiotics. (Table: $1 \& 2$ )

Out of 78 bacterial isolates the different degree of drug resistance strains are to be 
collected. In here 6(8\%) ESBL, 3(4\%) MDR, 1(1.2\%) MBL, 2(2.5\%) MRSA are identified (table $3 \&$ figure 3 ). The prevalence of MDR in this study, Klebsiella species (67\%), followed by Acinetobacter species (33.3\%).The prevalence of ESBL was the E.coli followed by Klebsiella spp, Pseudomonas spp \& Enterobacter spp.
The present study revealed high antibiotic resistance of Streptococcus species was noted on Tigecyclin (90.90\%), Linezilod (59.09\%), Pristinomicin (54.54\%). Antibiotic resistance of Klebsiella species was noted on Co-Trimoxazol (87.50\%), Amoxyclv (81.25\%), Netilmicin (75\%).

Table.1 Antibiotic resistant pattern of Gram positive isolates (\% resistance)

\begin{tabular}{|l|c|c|}
\hline Antibiotics & $\begin{array}{c}\text { Streptococcus } \\
\text { pyogens } \\
\mathrm{n}=18\end{array}$ & $\begin{array}{c}\text { Enterococcus } \\
\text { species } \\
\mathrm{n}=17\end{array}$ \\
\hline Ampicillin (AMP) & $11(61.11 \%)$ & $6(35.29 \%)$ \\
\hline Amoxyclav (AMC) & $6(33.33 \%)$ & $4(23.52 \%)$ \\
\hline Amikacin (AK) & $4(22.22 \%)$ & $2(11.76 \%)$ \\
\hline Clindamycin (CD) & $7(38.88 \%)$ & $10(58.82 \%)$ \\
\hline Co-Trimaxazole (COT) & $10(55.55 \%)$ & \\
\hline Erithromycin (E) & $11(61.11 \%)$ & $5(29.41)$ \\
\hline Linezolid (LZ) & $13(72.22 \%)$ & $3(17.64 \%)$ \\
\hline Pristinomycin (RP) & $12(66.66 \%)$ & $6(35.29 \%)$ \\
\hline Tigecyclin (TGC) & $16(88.88 \%)$ & $1(5.88 \%)$ \\
\hline Vancomycin (VA) & $3(16.66 \%)$ & $2(11.76 \%)$ \\
\hline
\end{tabular}

Table.2 Antibiotic resistant pattern of the Gram negative isolates (\% resistance)

\begin{tabular}{|l|c|c|}
\hline Antibiotic & Klebsiella species (n:16) & Pseudomonas species (n:9) \\
\hline Amikacin (AK) & $2(12.5 \%)$ & $4(44.44 \%)$ \\
\hline Amoxyclav (AMC) & $13(81.25 \%)$ & $4(44.44 \%)$ \\
\hline Aztreonam (AT) & $10(62.5 \%)$ & $3(33.33 \%)$ \\
\hline Ceftazidime (CAZ) & $8(50 \%)$ & $4(44.44 \%)$ \\
\hline Cefuroxime (CXM) & $11(68.75 \%)$ & $1(11.11 \%)$ \\
\hline Ciprofloxacin (CIP) & $2(12.5 \%)$ & $7(77.77 \%)$ \\
\hline Co-Trimoxazole (COT) & $14(87.5 \%)$ & $6(66.66 \%)$ \\
\hline Gentamicin (GEN) & $10(62.5 \%)$ & $3(33.33 \%)$ \\
\hline Imipenem (IPM) & $9(56.25 \%)$ & $3(33.33 \%)$ \\
\hline Meropenem (MRP) & $8(50 \%)$ & $3(33.33 \%)$ \\
\hline Netilmicin (NET) & $12(75 \%)$ & \\
\hline
\end{tabular}

In conclusion, the present study, report shows that more than half of the total cases were having significant RTI, with the majority coming from adult male patients. Out of the 100 bacterial isolates $9(50 \%)$
Streptococcus $\quad$ species, $\quad 16(20.51 \%)$ Klebsiella species \& $9 \quad(11.53 \%)$ Pseudomonas species were isolated. A significant prevalence of Streptococcal respiratory infections predominates. 
Out of the 100 isolates studied, 22 were fungal isolates. Among these 20 were Candida species \& 2 were Aspergillus species, which needed antifungal therapy for better responses.

The multiple drug resistance (MDR) among the isolates observed against the regularly used antibiotics is very high. The present study revealed that $8 \%$ ESBL, 4\% MDR, 1.2\% MBL, 2.5\% MRSA. Extended spectrum beta lactamases (ESBL) continue to be a major problem in clinical setups. Research in rapid molecular diagnosis should be encouraged to aid in rapid \& improved management of severe infections with resistant organisms. Isolation policies have to be adopted while handling colonized or infected patients with drug resistant organisms. Inappropriate \& irrational drug usage should be avoided. However, a combined approach of antibiotics restriction, effective surveillance \& good infection control practices is essential to overcome antibiotic resistance. The causative agents show the variety of drug resistance, so the possibility of reducing resistance by controlling the use of antibiotics is a logical approach.

\section{References}

Anderson, H., Esmail, A., Hollowell, J., Littlejohns, P., Strachen, D. 1993.
Epidemiologically based needs assessment: lower respiratory disease. DHA Project Research Programme: pp $6-12$.

Carroll, K.C. 2002. Laboratory Diagnosis of Lower Respiratory Tract Infections: Controversy \& Conundrums. J. Clin. Microbiol., 40(9): 3115-20.

Editorial. Antibiotics \& respiratory illness. 1974. Br. Med. J., 3: 1.

Elliot, T., Hastings, M., Desselberger, U. 1996. Lecture Notes on Medical Microbiology, Oxford: Blackwell Sciences.

Guthrie, R. 2001. Community-acquired lower respiratory tract infections: aetiology\& treatment; 20: 2021 - 34 .

Mukhopadhyay, C., Bhargava, A., Ayyagari, A. 2003. Role of mechanical ventilation \& development of multidrug resistant organisms in hospital acquired pneumonia. Indian $J$. Med. Res., 13: 296-300.

Woskey, H.J., Roding, T., Schulz, I., Lode, H. 2001. Ventilator associated pneumonia in a surgical intensive care unit: epidemiology, etiology \& comparison of tree bronchoscopic methods for microbiological specimen sampling. Critical Care, 5: 167-173.

\section{How to cite this article:}

Aswathi, K.P., B.J. Deepthy, Gogi Suresh, P.V. Harish and Deepthy, U.V. 2016. Prospective Study on Microbiology of Respiratory Tract Infections with Interest in Multidrug Resistant Bacteria. Int.J.Curr.Microbiol.App.Sci. 5(12): 291-294. doi: http://dx.doi.org/10.20546/ijcmas.2016.512.031 